Research Article

\title{
Enhancing the Activity and Stability of CuO/OMS-2 Catalyst for CO Oxidation at Low Temperature by Modification with Metal Oxides
}

\author{
Nhat Huy Nguyen $\mathbb{D}^{1,2}$ Bich Thao Nguyen Thi, ${ }^{1,2}$ Thao Giang Nguyen Le, ${ }^{1,2}$ \\ Quynh Anh Nguyen Thi, ${ }^{2,3}$ Phuoc Toan Phan, ${ }^{2,4}$ Long Giang Bach, \\ and Trung Thanh Nguyen (iD) \\ ${ }^{1}$ Faculty of Environment and Natural Resources, Ho Chi Minh City University of Technology (HCMUT), 268 Ly Thuong Kiet St.,
Dist. 10, Ho Chi Minh City, Vietnam
${ }^{2}$ Vietnam National University Ho Chi Minh City, Linh Trung Ward, Thu Duc District, Ho Chi Minh City, Vietnam
${ }^{3}$ Laboratory of Nanomaterial, An Giang University, 18 Ung Van Khiem St, Dong Xuyen Ward, Long Xuyen City,
An Giang Province, Vietnam
${ }^{4}$ Faculty of Engineering-Technology-Environment, An Giang University, 18 Ung Van Khiem St, Dong Xuyen Dist.,
Long Xuyen City, An Giang Province, Vietnam
${ }^{5}$ NTT Institute of High Technology, Nguyen Tat Thanh University, 298-300A Nguyen Tat Thanh, Ho Chi Minh City, Vietnam
}

Correspondence should be addressed to Trung Thanh Nguyen; ntthanh@agu.edu.vn

Received 12 March 2020; Accepted 19 July 2020; Published 3 August 2020

Academic Editor: João Claudio Thomeo

Copyright (c) 2020 Nhat Huy Nguyen et al. This is an open access article distributed under the Creative Commons Attribution License, which permits unrestricted use, distribution, and reproduction in any medium, provided the original work is properly cited.

\begin{abstract}
In this study, mixed oxides of $\mathrm{Mn}-\mathrm{Cu}$ and $\mathrm{Fe}-\mathrm{Cu}$ on OMS-2 support having an octahedral structure were synthesized by the refluxing and impregnation methods. The characteristics of the materials were analyzed by XRD, FTIR, SEM, EDX, and $\mathrm{H}_{2}-$ TPR. In the $\mathrm{CO}$ oxidation test, $\mathrm{CuFeO}_{x} / \mathrm{OMS}-2$ had slightly higher catalytic activity but is significantly more stable than $\mathrm{CuMnO}_{x} / \mathrm{OMS}-2$ and CuO/OMS-2. Due to its lower reduction temperature in $\mathrm{H}_{2}$-TPR analysis, the Mars-Van-Krevelen mechanism for $\mathrm{CuFeO}_{x} / \mathrm{OMS}-2\left(\mathrm{Cu}^{2+}-\mathrm{O}-\mathrm{Fe}^{3+} \leftrightarrow \mathrm{Cu}^{+}-\square-\mathrm{Fe}^{2+}\right)$ could take place more energetically than CuO/OMS-2 and $\mathrm{CuMnO}_{x} / \mathrm{OMS}-2\left(\mathrm{Cu}^{2+}-\mathrm{O}^{2-}-\mathrm{Mn}^{4+} \leftrightarrow \mathrm{Cu}^{+}-\square-\mathrm{Mn}^{3+}\right)$. In addition, the interaction between $\mathrm{Fe}$ and $\mathrm{Cu}$ in the catalyst could improve the durability of the surface oxides structure in comparison with that between $\mathrm{Mn}$ and $\mathrm{Cu}$. With the high specific rate and TOF of $28.6 \mathrm{mmol} / \mathrm{h}$.g and 0.508 , respectively, $\mathrm{CuFeO}_{x} / \mathrm{OMS}-2$ has a great potential as an effective catalyst for lowtemperature oxidation application in $\mathrm{CO}$ and possible VOCs removal.
\end{abstract}

\section{Introduction}

Air pollution by $\mathrm{CO}$ has recently been considered to be one of the serious problems in the developing countries due to the increasing consumption of fuels and especially biomass with low combustion efficiency [1]. There are many ways for CO treatment, in which catalytic CO oxidation is considered as one of the most effective and energy-saving techniques [2-4]. In general, precious metal catalysts based on Pt-group have high efficiency in $\mathrm{CO}$ oxidation at low temperature, but they are expensive and precious metals $[2,5-7]$. To reduce the cost, several studies have been done to look for oxides of transition metals (e.g., $\mathrm{Mn}, \mathrm{Co}, \mathrm{Ce}, \mathrm{Cu}, \mathrm{Mo}$, and Fe). Among them, copper oxide and its combination with other metals have been of special interest and hopcalite $\left(\mathrm{CuMnO}_{x}\right)$ is one of the most popular catalysts for low-temperature oxidation of $\mathrm{CO}[8,9]$.

Octahedral molecular sieve (OMS-2), a cryptomelane type of manganese oxides, is a promising catalyst for applications in oxidation reactions due to its high activity, high 
selectivity, and good catalytic durability [10]. Liu et al. [11] combined $\mathrm{CuO}$ and OMS-2 for $\mathrm{CO}$ oxidation at low temperature and reported that the good dispersion and the interaction between copper oxide and manganese oxide in $\mathrm{CuO} / \mathrm{OMS}-2$ catalyst produce active sites for the oxidation of $\mathrm{CO}$, which can be explained by Mars-Van-Krevelen mechanism, whereby the redox pair $\mathrm{Cu}^{2+}-\mathrm{O}^{2-}-\mathrm{Mn}^{4+} \leftrightarrow \mathrm{Cu}^{+}-\square-\mathrm{Mn}^{3+} \quad(\square-$ oxygen vacancy) took place. After that, the $\mathrm{CuMnO}_{x} / \mathrm{OMS}-2$ catalyst was prepared for increasing the interaction between copper oxide and manganese oxide on the surface of OMS-2 support and, therefore, improving the catalytic activity in CO oxidation at low temperature [12]. However, the role of redox pairs in the transition metal oxide catalyst structure and the effect of adding metal oxides on the stability of $\mathrm{CuO}$ catalysts on OMS-2 support have not been well understood yet.

On the other hand, the combination of $\mathrm{Cu}$ and Fe oxides for $\mathrm{CO}$ oxidation at low temperatures was also reported in several studies [13]. Cao et al. [14] reported that mesoporous $\mathrm{CuO}-\mathrm{Fe}_{2} \mathrm{O}_{3}$ composite produced by the surfactant-assisted method with wormhole-like mesostructure gave high catalytic activity and stability for the oxidation of CO. Amini et al. [15] synthesized mesoporous $\mathrm{CuFe}_{2} \mathrm{O}_{4}$ nanopowders via the sol-gel method and declared that the addition of $\mathrm{Cu}$ into iron oxide affected its properties and yielded high catalytic stability for $\mathrm{CO}$ oxidation. Yeste et al. [16] used $\mathrm{Cu}-$ Fe mixed oxides $\left(\mathrm{CuFe}_{2} \mathrm{O}_{4}\right)$ fabricated by the coprecipitation method at low temperature as an effective catalyst for $\mathrm{CO}$ oxidation with high stability. Rezaei et al. [17] prepared mesoporous nanopowders of iron and copper mixed oxides by the simple one-pot solid-state method, and the results showed that the spinel structure gave the best $\mathrm{CO}$ oxidation ability without obvious deactivation. Hence, there is a great potential for the combination of $\mathrm{CuFeO}_{x}$ catalysts with OMS-2 support not only to enhance the oxidation ability at a lower temperature, but also to improve the stability of the catalyst. However, to the best of our knowledge, the application of such $\mathrm{CuFeO}_{x} / \mathrm{OMS}-2$ material synthesized by a facile impregnation method has not been reported yet.

In this study, $\mathrm{CuFeO}_{x} / \mathrm{OMS}-2$ catalyst was synthesized by adding $\mathrm{Fe}^{3+}$ into the structure of $\mathrm{CuO}$ catalyst to compare the efficiency of its redox pair $\left(\mathrm{Cu}^{2+}-\mathrm{O}^{2-}-\mathrm{Fe}^{3+} \leftrightarrow \mathrm{Cu}^{+}-\square-\mathrm{Fe}^{2+}\right)$ to that of $\mathrm{CuMnO}_{x} / \mathrm{OMS}-$ $2\left(\mathrm{Cu}^{2+}-\mathrm{O}^{2-}-\mathrm{Mn}^{4+} \leftrightarrow \mathrm{Cu}^{+}-\square-\mathrm{Mn}^{3+}\right)$ in $\mathrm{CO}$ oxidation at low temperature. Furthermore, this study was also conducted to demonstrate a multidimensional view of the MarsVan-Krevelen mechanism to find out potential catalysts for efficient oxidation of $\mathrm{CO}$ at low temperatures.

\section{Materials and Methods}

2.1. Preparation for Catalysts. Analytical-grade chemicals such as $\mathrm{Cu}\left(\mathrm{NO}_{3}\right)_{3}, \mathrm{Fe}\left(\mathrm{NO}_{3}\right)_{3}, \mathrm{Mn}\left(\mathrm{NO}_{3}\right)_{2}$, and standard solutions of iron, and copper and manganese used in this study were purchased from Sigma Aldrich and Merck and used directly without further purification.

OMS-2 support was synthesized by the refluxing method according to DeGuzman et al. [10]. The synthesis process can be described basically as follows. At first, $11.33 \mathrm{~g}$ of $\mathrm{MnSO}_{4} \cdot \mathrm{H}_{2} \mathrm{O}$ (analytical-grade, Xilong, China) was dissolved in $120 \mathrm{~mL}$ of deionized (DI) water (solution A), while $7.57 \mathrm{~g}$ of $\mathrm{KMnO}_{4}$ (analytical-grade, Xilong, China) was dissolved in $38 \mathrm{~mL}$ of DI water (solution B). The two solutions were then mixed thoroughly and added with $4 \mathrm{~mL}$ of concentrated $\mathrm{HNO}_{3}$, which was followed by refluxing at $100^{\circ} \mathrm{C}$ for $24 \mathrm{~h}$. The brown solid product was subsequently separated by filtration and washed several times with DI water until the $\mathrm{pH}$ of about 7 was reached. The OMS-2 product was finally obtained after drying at $120^{\circ} \mathrm{C}$ overnight and calcined at $400^{\circ} \mathrm{C}$ for $4 \mathrm{~h}$.

The catalysts, including $\mathrm{CuMnO}_{x} / \mathrm{OMS}-2$ and $\mathrm{CuFeO}_{x} / \mathrm{OMS}-2$ with 15 wt. $\%$ of $\mathrm{CuMnO}_{x}$ and $\mathrm{CuFeO}_{x}$, were then prepared by impregnation method using the prepared OMS-2 support [11, 12]. The OMS-2 support was impregnated in a solution containing $250 \mathrm{~mL}$ of DI water and appropriate amounts of $\mathrm{Cu}\left(\mathrm{NO}_{3}\right)_{2}$ and $\mathrm{Mn}\left(\mathrm{NO}_{3}\right)_{2}$ or $\mathrm{Fe}\left(\mathrm{NO}_{3}\right)_{3}$ salts. Afterward, the mixture was heated at $80^{\circ} \mathrm{C}$ while being stirred to remove water and followed by drying at $100^{\circ} \mathrm{C}$ and annealing at $400^{\circ} \mathrm{C}$ for $4 \mathrm{~h}$.

2.2. Material Characterization. Wide-angle X-ray diffraction (XRD) patterns, which were collected by an XRD 300W diffractometer (D2 Phaser, Bruker) with a $\mathrm{CuK}_{\alpha}$ radiation wavelength of $1.5406 \AA$ having a step size of $0.05^{\circ}$ and a step time of $30 \mathrm{~s}$, were used to analyze the material crystalline structure. The morphology and particle size of $\mathrm{CuMnO}_{x} /$ OMS-2 and $\mathrm{CuFeO}_{x} / \mathrm{OMS}-2$ were evaluated using scanning electron microscopy (SEM) with energy-dispersive X-ray spectroscopy (EDS) (JSM-IT200, JEOL) and transmission electron microscopy (TEM) on a Philips Tecnai G ${ }^{2}$ F20 TEM microscope operated at $40 \mathrm{kV}$. The samples were prepared by ultrasonically suspending the materials in ethanol, and the suspension was then applied to a copper grid and dried in an oven. Another method of determining specific surface area and pore size of the materials was the Brunauer-Emmett-Teller (BET) analysis. The analysis was conducted at $77 \mathrm{~K}$ using a BET-202A system (Porous Materials Inc.), in which nitrogen was used as an adsorbate for probing the surface of the materials. It should be noted that BET analysis was carried out after the materials were degassed at $150^{\circ} \mathrm{C}$ for 4 hours to remove the water from the oxide meso-/micropores thoroughly. An inductively coupled plasma atomic emission spectrometry (ICP-AES, iCAP 6500, Thermo Scientific) was utilized to measure the amount of $\mathrm{CuMnO}_{x}$ and $\mathrm{CuFeO}_{x}$ adhering to the OMS-2 support by determining the $\mathrm{Cu}, \mathrm{Fe}$, and $\mathrm{Mn}$ contaminations in $\mathrm{Mn}\left(\mathrm{NO}_{3}\right)_{2}, \mathrm{Fe}\left(\mathrm{NO}_{3}\right)_{3}$, and $\mathrm{Cu}\left(\mathrm{NO}_{3}\right)_{2}$ solutions.

2.3. Measurement of Catalytic Activity. A quartz tubular fixed bed reactor with an internal diameter of $10 \mathrm{~mm}$, which was employed for $\mathrm{CO}$ oxidation under atmospheric pressure, was loaded up with $200 \mathrm{mg}$ of the catalysts. During the oxidation, the reaction temperature was monitored continuously by a thermocouple placed in the middle of the catalyst bed. A mixture of 1 vol.\% $\mathrm{CO}$ and 1 vol. $\% \mathrm{O}_{2}$, as the reactants with a total gas flow rate of $30 \mathrm{~mL} \cdot \mathrm{min}^{-1}$ (space 
velocity of $12,000 \mathrm{~mL} \cdot \mathrm{g}^{-1} \cdot \mathrm{h}^{-1}$ ), balanced in nitrogen, was passed through the reactor. The $\mathrm{CO}$ and $\mathrm{CO}_{2}$ were analyzed by a gas chromatograph (GC, Trace-GC 1310, Thermo Scientific) equipped with a flame ionization detector (FID) and a TR-WaxMS GC column. The carbon-containing gaseous products were conducted to a methanation converter filled with Raney-Ni catalyst before going to the detector to ensure obtaining signals with high intensity [11].

\section{Results and Discussion}

3.1. Material Synthesis and Characterization. The morphology is one of the important properties of the catalysts, which could show the shape, size, and even crystalline property of the catalyst particles. Figure 1 shows the TEM image of $\mathrm{CuFeO}_{x} / \mathrm{OMS}-2$ catalyst at low and high resolutions. It was apparent that the $\mathrm{CuFeO}_{x} / \mathrm{OMS}-2$ has nanorodshaped morphology, with a diameter of approximately $13 \mathrm{~nm}$ and length from 300 to $500 \mathrm{~nm}$. This result is consistent with that in the study of Zhang et al. [18] reported on related OMS-2 materials.

In addition, $\mathrm{CuMnO}_{x} / \mathrm{OMS}-2$ and $\mathrm{CuFeO}_{x} / \mathrm{OMS}-2$ catalysts were also analyzed with the SEM-EDS, and the results are shown in Figures 2 and 3. For $\mathrm{CuMnO}_{x} / \mathrm{OMS}-2$ sample (Figure 2), the $\mathrm{Cu}$ and $\mathrm{Mn}$ components were evenly distributed on the surface of OMS-2 support. It was discovered that the results were similar to those of $\mathrm{CuFeO}_{x} / \mathrm{OMS}-2$ sample (Figure 3 ). There was an agreement in the calculation and the analysis results of $\mathrm{CuMnO}_{x}$ and $\mathrm{CuFeO}_{x}$ contents adhering to OMS-2 support, which were determined by ICPAES. The atomic percentage of elements on the surface of the catalysts is summarized in Table 1.

The XRD patterns of the catalysts are displayed in Figure 4. It has been observed that the diffraction peaks at $2 \theta$ of $12.6^{\circ}, 17.9^{\circ}, 28.7^{\circ}, 37.5^{\circ}, 41.9^{\circ}, 49.9^{\circ}$, and $60.1^{\circ}$ directly contributed to the crystalline phase of cryptomelane $\left(\mathrm{KMn}_{8} \mathrm{O}_{16}\right)$, proving that the nanorod OMS-2 material had a cryptomelane-type structure [19], corresponding to the XRD patterns of OMS-2 material in some works $[18,19]$. Although appearing at relatively low intensity, the diffraction peaks at $2 \theta$ of $32.6^{\circ}, 35.5^{\circ}$, and $38.8^{\circ}$ in XRD patterns of $\mathrm{Cu}-$ containing catalysts could be attributed to its low crystalline phase of copper oxide [11]. Meanwhile, peaks at $23^{\circ}$ and $25.5^{\circ}$ in the XRD pattern of $\mathrm{CuFeO}_{x} / \mathrm{OMS}-2$ catalyst are indexed to the crystalline phase of ferric oxide.

Figure 5 illustrates the FTIR patterns of catalysts including OMS-2, CuO/OMS-2, $\mathrm{CuMnO}_{x} / \mathrm{OMS}-2$, and $\mathrm{CuFeO}_{x} / \mathrm{OMS}-2$. In $\mathrm{CuMnO}_{x} / \mathrm{OMS}-2$ catalyst, the FTIR patterns, to a large extent, were characterized by the vibration peaks of $\mathrm{Cu}-\mathrm{O}-\mathrm{Cu}$ at 410,420 , and $430 \mathrm{~cm}^{-1}$ and of $\mathrm{Cu}-\mathrm{O}$ at $440 \mathrm{~cm}^{-1}$ [20]. Similarly, the FTIR pattern in $\mathrm{CuFeO}_{x} / \mathrm{OMS}-2$ catalyst was also characterized by the vibrations of the same peaks above. Nevertheless, differences between the vibrations below $500 \mathrm{~cm}^{-1}$ were observed, which determined that these vibrations were of $\mathrm{Fe}-\mathrm{O}$. Moreover, these results were also found to be consistent with the XRD patterns of both materials.

The redox characteristics of the catalysts are often determined by $\mathrm{H}_{2}$-TPR. Figure 6 compares $\mathrm{H}_{2}$-TPR profiles of $\mathrm{CuO} / \mathrm{OMS}-2, \mathrm{CuMnO}_{x} / \mathrm{OMS}-2$, and $\mathrm{CuFeO}_{x} /$ OMS-2 catalysts at different temperature ranges. In all catalysts, $\gamma_{1}$ and $\gamma_{2}$ peaks present the two reduction steps of manganese oxide, where $\gamma_{1}$ peak is for the first reduction step of $\mathrm{MnO}_{2} / \mathrm{Mn}_{2} \mathrm{O}_{3}$ to $\mathrm{Mn}_{3} \mathrm{O}_{4}$ and $\gamma_{2}$ peak is for the second reduction step of $\mathrm{Mn}_{3} \mathrm{O}_{4}$ to $\mathrm{MnO}$ [11]. There were shifts of $\gamma_{1}$ and $\gamma_{2}$ peaks to lower reduction temperature in CuMnO $x /$ OMS-2 and $\mathrm{CuFeO}_{x} / \mathrm{OMS}-2$ as compared to $\mathrm{CuO} / \mathrm{OMS}-2$ catalyst, and the peaks of $\mathrm{CuFeO}_{x} / \mathrm{OMS}-2$ were the lowest ones (Table 2). It can be stated that the presence of $\mathrm{Cu}$ and $\mathrm{Fe}$ encouraged the reducibility of manganese oxide via an $\mathrm{H}$-spillover effect [21]. Furthermore, the $\alpha$ peak resulted in the reduction of the $\mathrm{CuO}_{x}$ species having strong interaction with manganese and ferric oxides, while the $\beta$ peak was responsible for the reduction of highly dispersed $\mathrm{CuO}_{x}$ species on the catalyst surface, which had a weak interaction with the surface manganese and ferric oxides [22]. In general, the $\alpha$ and $\beta$ peaks of $\mathrm{CuMnO}_{x} / \mathrm{OMS}-2$ and $\mathrm{CuFeO}_{x} / \mathrm{OMS}-2$ were at lower temperatures than those of $\mathrm{CuO} / \mathrm{OMS}-2$, particularly for $\mathrm{CuFeO}_{x} / \mathrm{OMS}-2$ at the lowest temperatures (Table 2), which is due to the strong interaction of oxides in the catalyst structure. The $\beta$ peak is also assigned to the reduction of large $\mathrm{CuO}$ particles as well as the reduction of $\mathrm{MnO}_{2}$ to $\mathrm{Mn}_{3} \mathrm{O}_{4}[11,23]$. There was another peak observed at $200^{\circ} \mathrm{C}$ for $\mathrm{CuFeO}_{x} / \mathrm{OMS}-2$ catalyst, which is ascribed to the reduction of $\mathrm{Fe}_{2} \mathrm{O}_{3}$ to $\mathrm{Fe}_{3} \mathrm{O}_{4}$ [21]. Besides, when applying mesoporous $\mathrm{CuO}-\mathrm{Fe}_{2} \mathrm{O}_{3}$ for $\mathrm{CO}$ oxidation, $\mathrm{Cao}$ et al. [14] found that this reduction peak is at a lower temperature than that of iron oxide, possibly due to the strong interaction of iron oxide and copper oxide in the structure of $\mathrm{CuO}-\mathrm{Fe}_{2} \mathrm{O}_{3}$ composite.

3.2. CO Oxidation Test. Table 3 lists CO oxidation performances of catalysts, composed of OMS-2, CuO/OMS-2, $\mathrm{CuMnO}_{x} / \mathrm{OMS}-2$, and $\mathrm{CuFeO}_{x} / \mathrm{OMS}-2$, in several studies. It is important to notice that the obtained catalysts were made into pellets and sieved to enhance the stability under the effect of a high gas flow rate in the reactor. From the results in Table 3, it is obvious that all CuO-supported OMS-2 catalysts showed very high activities for $\mathrm{CO}$ oxidation at a room temperature of roughly $35^{\circ} \mathrm{C}$, while OMS-2 had no activity. The specific reaction rate of $\mathrm{CO}$ oxidation of $\mathrm{CuFeO}_{x} / \mathrm{OMS}-2$ catalyst was $28.6 \mathrm{mmol} \mathrm{CO} \cdot \mathrm{h}^{-1} \cdot \mathrm{g}_{\mathrm{Cu}}{ }^{-1}$, which is slightly higher than those of $\mathrm{CuMnO}_{x} / \mathrm{OMS}-2\left(27.8 \mathrm{mmol} \cdot \mathrm{h}^{-1} \cdot \mathrm{g}^{-1}\right)$ and CuO/OMS-2 (27.2 mmol. $\left.\mathrm{h}^{-1} \cdot \mathrm{g}^{-1}\right)$ catalysts. The TOF of the catalysts is in the order of $\mathrm{CuFeO}_{x} / \mathrm{OMS}-2$ (0.508) $>\mathrm{CuMnO}_{x} / \mathrm{OMS}-2$ (0.495) > CuO/OMS-2 (0.484), indicating that the presence of $\mathrm{Fe}$ and $\mathrm{Mn}$ components in the $\mathrm{CuO}$ structure could enhance the catalytic activity of CuO/OMS-2 catalyst. It could be explained by the existence of two redox pairs $\mathrm{Cu}^{2+}-\mathrm{O}^{2-}-\mathrm{Fe}^{3+} \leftrightarrow \mathrm{Cu}^{+}-\square-\mathrm{Fe}^{2+}+\mathrm{O}_{2}$ and $\mathrm{Cu}_{2}{ }^{+}-\mathrm{O}^{2-}-\mathrm{Mn}^{4+} \leftrightarrow \mathrm{Cu}^{+}-\square-\mathrm{Mn}^{3+}+\mathrm{O}_{2}$ in structures of $\mathrm{CuFeO}_{x} / \mathrm{OMS}-2$ and $\mathrm{CuMnO}_{x} / \mathrm{OMS}-2$ catalysts, respectively. On the other hand, a higher catalytic activity of $\mathrm{CuFeO}_{x} /$ OMS- 2 catalyst as against $\mathrm{CuMnO}_{x} / \mathrm{OMS}-2$ catalyst could be due to the lower redox potential of $\mathrm{Fe}^{3+} / \mathrm{Fe}^{2+}$ compared to that of $\mathrm{Mn}^{4+} / \mathrm{Mn}^{3+}$. Consequently, the reduction process of 


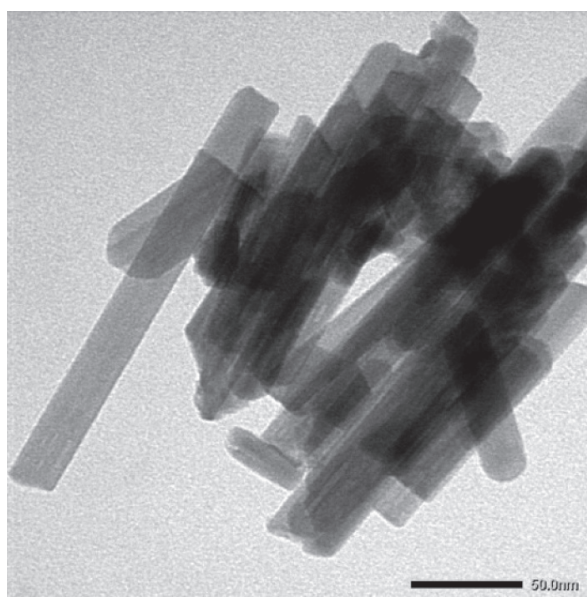

(a)

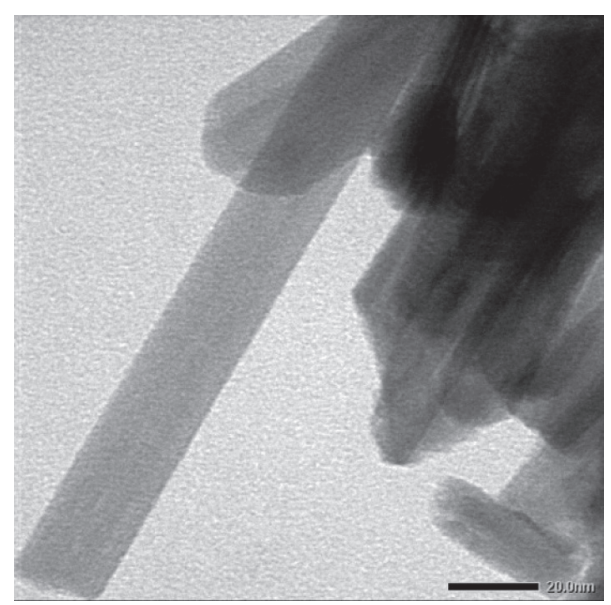

(b)

Figure 1: TEM images of $\mathrm{CuFeO}_{x} / \mathrm{OMS}-2$ material at low and high resolutions.

$\operatorname{IMG1}\left(1^{\mathrm{st}}\right)$

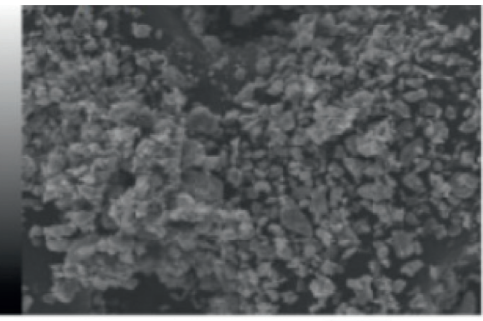

$50 \mu \mathrm{m}$
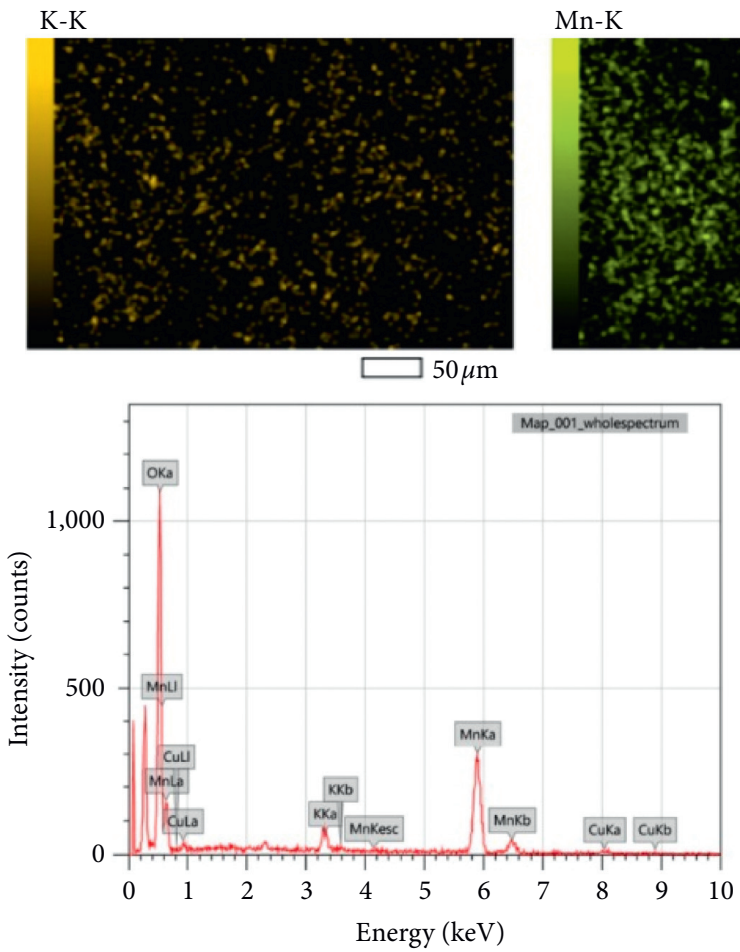

IMG1

Mn-K
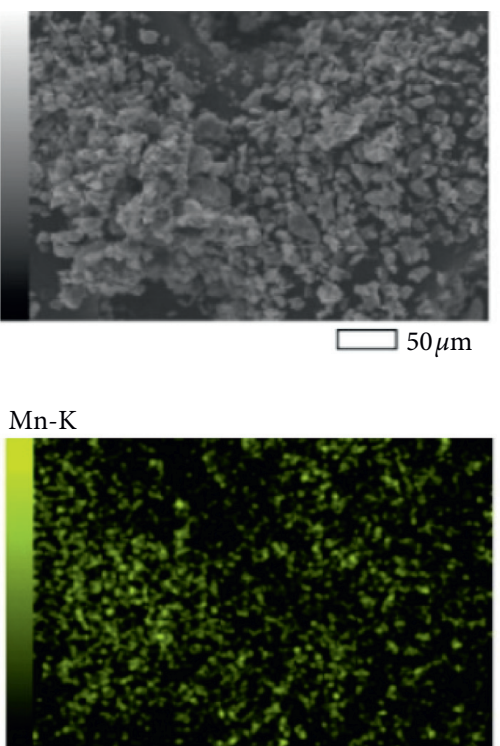

$\square 50 \mu \mathrm{m}$

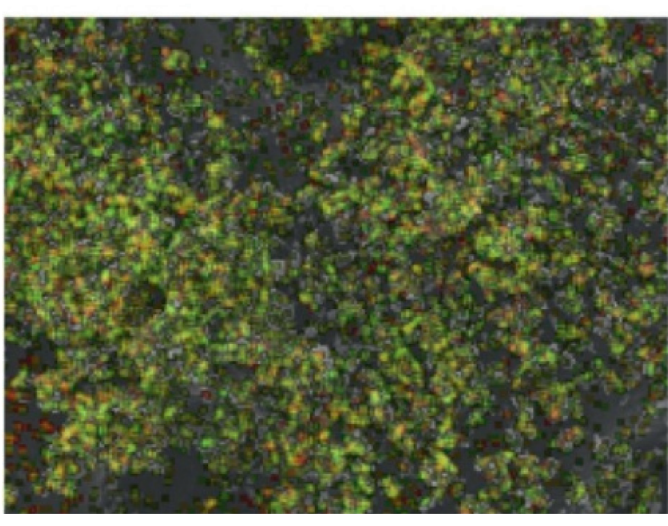

O-K $\quad \mathrm{Mn}-\mathrm{K}$
O-K

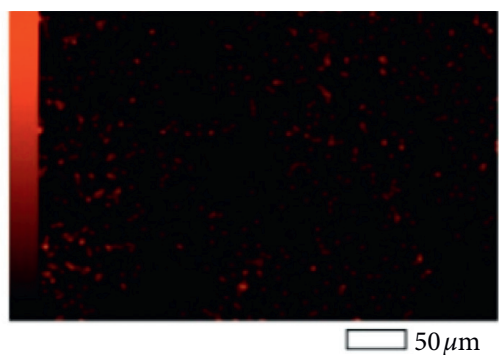

$\mathrm{Cu}-\mathrm{K}$

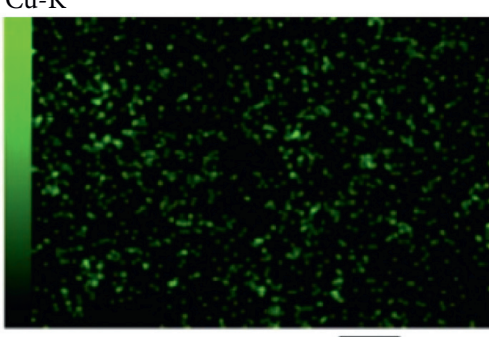

$\square 50 \mu \mathrm{m}$

FIgURE 2: SEM-mapping and EDS images of $\mathrm{CuMnO}_{x} / \mathrm{OMS}-2$ catalyst. 


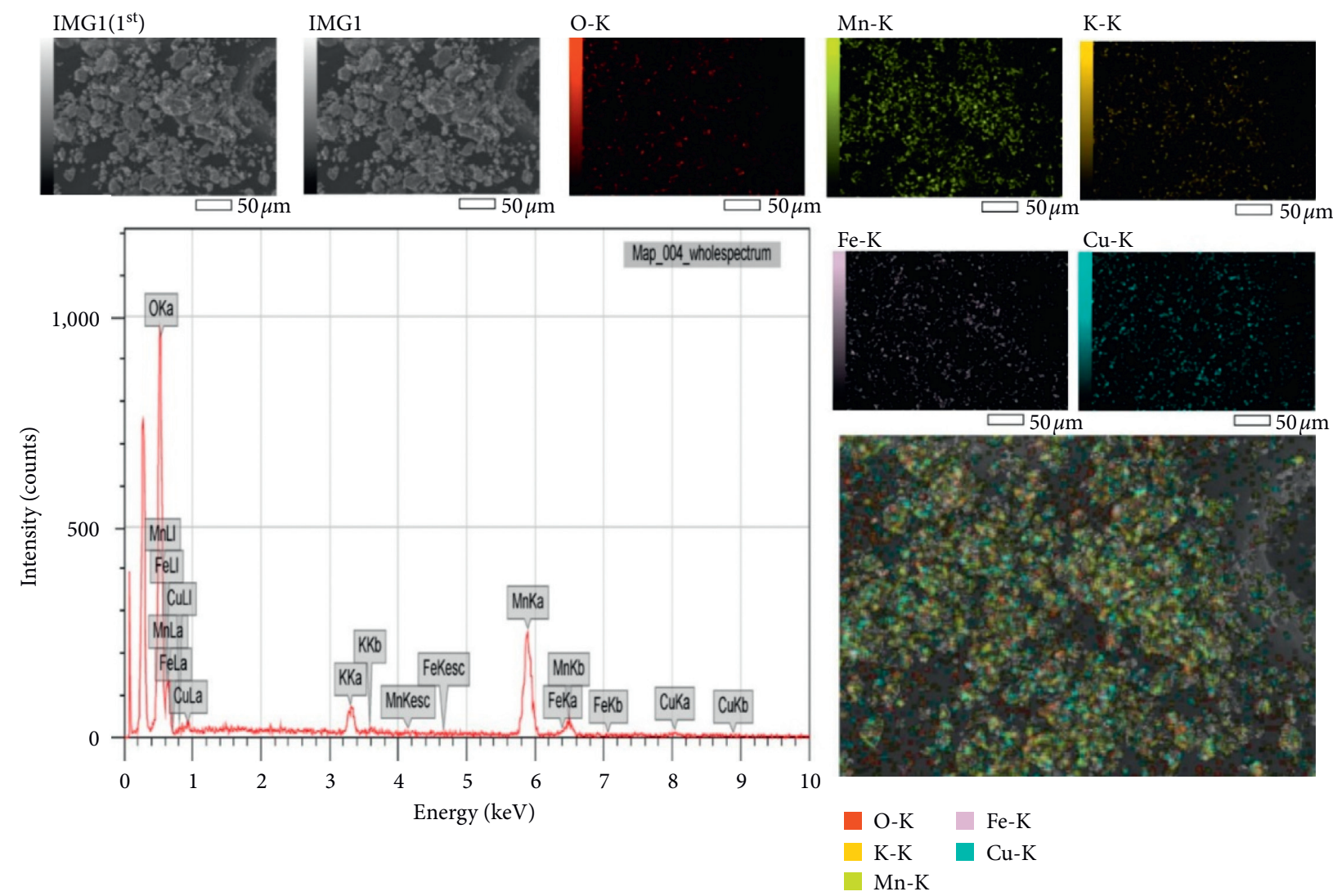

Figure 3: SEM-mapping and EDS images of $\mathrm{CuFeO}_{x} / \mathrm{OMS}-2$ catalyst.

TABLE 1: Elemental composition in the atomic percentage of the catalysts by EDS.

\begin{tabular}{lccccc}
\hline Catalyst & $\mathrm{O}$ & $\mathrm{K}$ & $\mathrm{Mn}$ & $\mathrm{Cu}$ & \\
\hline $\mathrm{CuMnO}_{x} / \mathrm{OMS}-2$ & 65.85 & 2.98 & 29.61 & $\mathrm{Fe}$ \\
$\mathrm{CuFeO}_{x} / \mathrm{OMS}-2$ & 66.68 & 3.09 & 26.48 & 1.56 & 1.52 \\
\hline
\end{tabular}

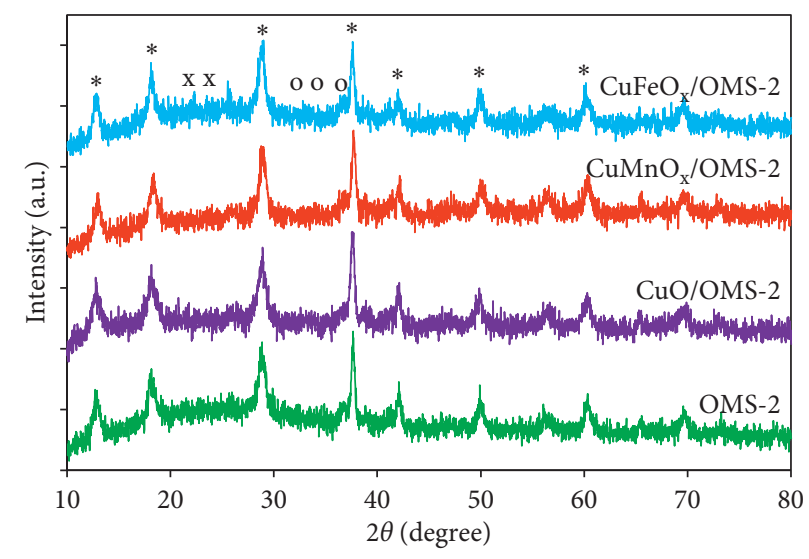

Figure 4: XRD patterns of OMS-2, CuO/OMS-2, $\mathrm{CuMnO}_{x} / \mathrm{OMS}-2$, and $\mathrm{CuFeO}_{x} / \mathrm{OMS}-2$ samples ( ${ }^{*}$ : cryptomelane, o copper oxide, and $x$ ferric oxide).

$\mathrm{CuFeO}_{x}$ took place more smoothly than that of $\mathrm{CuMnO}_{x}$, and thus it is more active and easily activated for $\mathrm{CO}$ oxidation at low temperatures.
Durability, which is an important aspect, is often of great interest when studying the catalyst for chemical reactions. Here, the catalytic durability was evaluated via the specific 


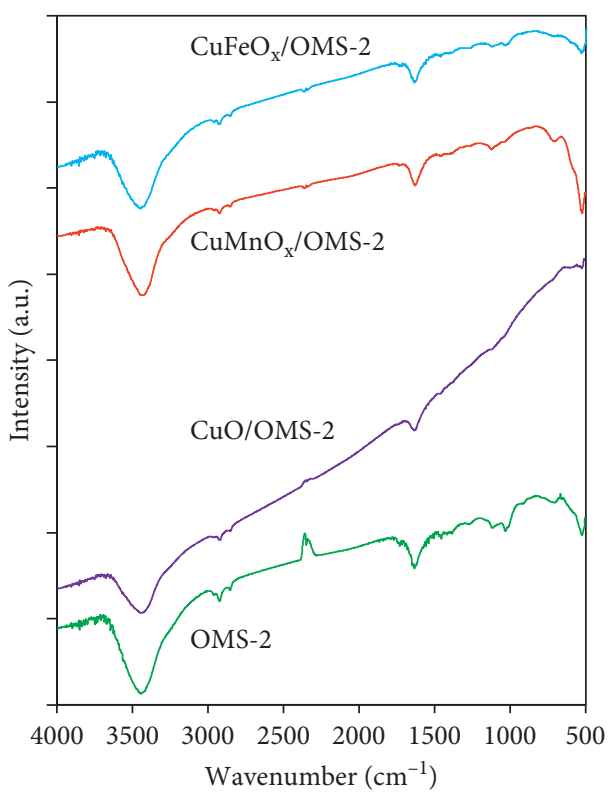

(a)

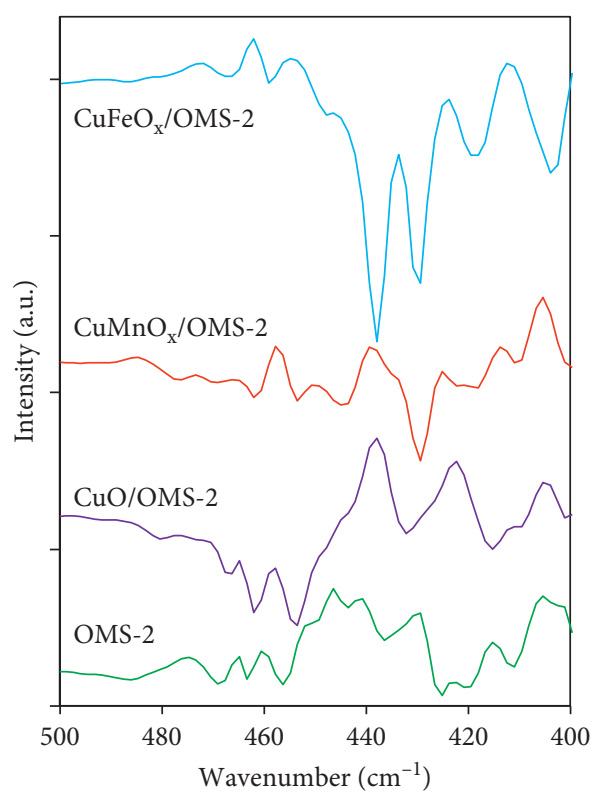

(b)

FIgURE 5: FTIR patterns of OMS-2, CuO/OMS-2, $\mathrm{CuMnO}_{x} / \mathrm{OMS}-2$, and $\mathrm{CuFeO}_{x} / \mathrm{OMS}-2$ samples in the range of (a) $500-4000 \mathrm{~cm}^{-1}$ and (b) $400-500 \mathrm{~cm}^{-1}$.

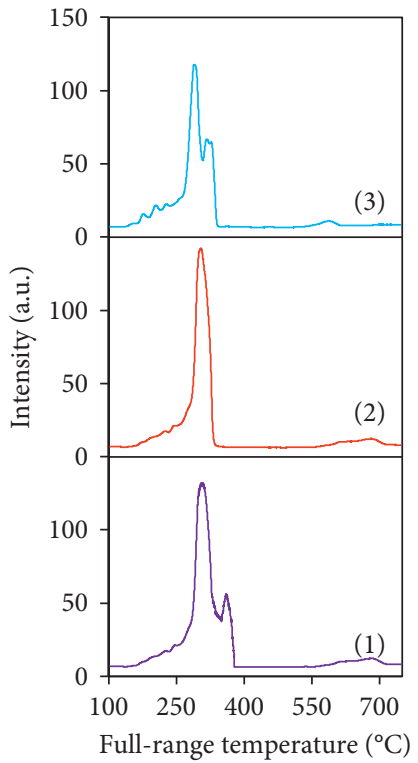

(a)

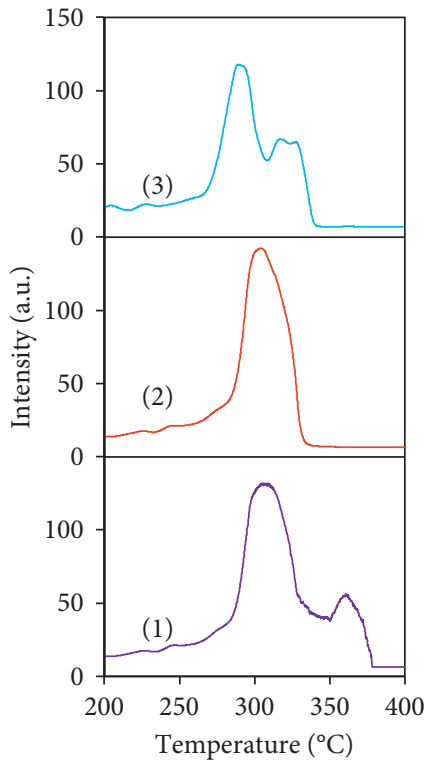

(b)

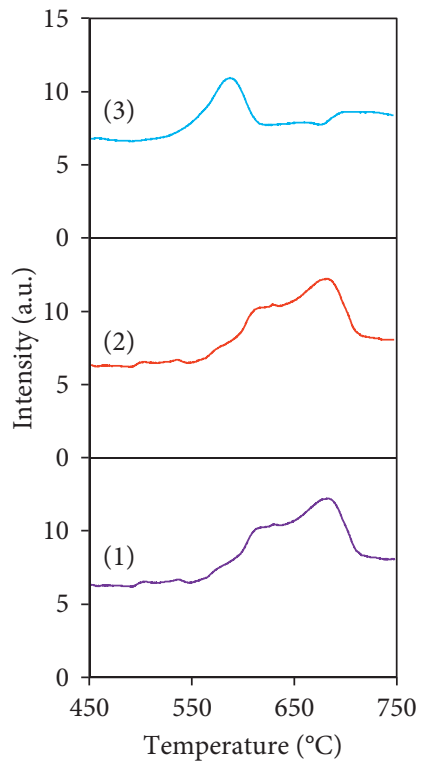

(c)

Figure 6: TPR patterns of catalysts with different temperature ranges: (1) CuO/OMS-2, (2) $\mathrm{CuMnO}_{x} / \mathrm{OMS}-2$, and (3) CuFeO $x / \mathrm{OMS}-2$.

TABLE 2: The reduction temperature of peaks in $\mathrm{H}_{2}$-TPR profile of catalysts.

\begin{tabular}{lcccccc}
\hline Catalyst & $\alpha\left({ }^{\circ} \mathrm{C}\right)$ & $\delta\left({ }^{\circ} \mathrm{C}\right)$ & $\beta\left({ }^{\circ} \mathrm{C}\right)$ & $\gamma_{1}\left({ }^{\circ} \mathrm{C}\right)$ & $\gamma_{2}\left({ }^{\circ} \mathrm{C}\right)$ & 400 \\
\hline $\mathrm{CuO} / \mathrm{OMS}-2$ & 180 & - & 275 & 350 & Note \\
$\mathrm{CuMnO}_{x} / \mathrm{OMS}-2$ & 170 & - & 245 & 310 & 330 & This study \\
$\mathrm{CuFeO}_{x} / \mathrm{OMS}-2$ & 160 & 200 & 230 & 290 & 320 & This study \\
\hline
\end{tabular}

rate of catalyst in $\mathrm{CO}$ oxidation at room temperature after 48 h of operation (Figure 7 ). The stability of the CuO/OMS-2 increased significantly after adding manganese oxide and especially iron oxide into the structure of $\mathrm{CuO}$. After $48 \mathrm{~h}$ of reaction, the activity of $\mathrm{CuFeO}_{x} / \mathrm{OMS}-2$ only reduced by $16.8 \%$, which was much lower than those of $55.4 \%$ and 
Table 3: Performance of catalysts for CO oxidation.

\begin{tabular}{|c|c|c|c|c|c|}
\hline Catalyst & Surface area $\left(\mathrm{m}^{2} / \mathrm{g}\right)$ & Reaction temperature $\left({ }^{\circ} \mathrm{C}\right)$ & Specific rate $\left(\mathrm{mmol} \mathrm{CO} \cdot \mathrm{h}^{-1} \cdot \mathrm{g}_{\mathrm{Cu}}{ }^{-1}\right)$ & TOF & Note/reference \\
\hline OMS-2 & 48.5 & $\sim 35$ & 0 & - & This study \\
\hline $\mathrm{CuO} / \mathrm{OMS}-2$ & - & 20 & 24.5 & 0.436 & [11] \\
\hline $\mathrm{CuO} / \mathrm{OMS}-2$ & 41.4 & $\sim 35$ & 27.2 & 0.484 & [12] \\
\hline $\mathrm{CuMnO}_{x} / \mathrm{OMS}-2$ & 52.76 & $\sim 35$ & 27.8 & 0.495 & This study \\
\hline $\mathrm{CuFeO}_{x} / \mathrm{OMS}-2$ & 52.40 & $\sim 35$ & 28.6 & 0.508 & This study \\
\hline
\end{tabular}

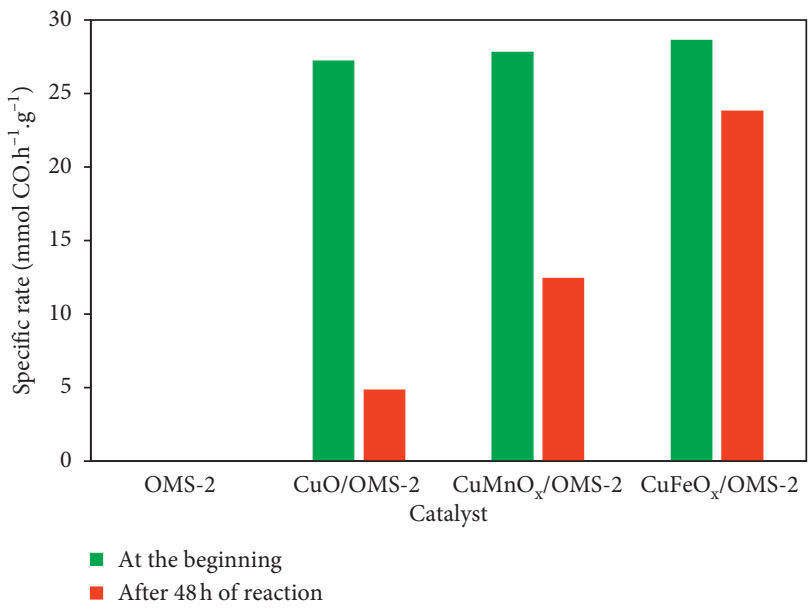

FIgURE 7: Specific rate of catalysts at room temperature at the beginning and after $48 \mathrm{~h}$ of $\mathrm{CO}$ oxidation.

82.4\% in $\mathrm{CuMnO}_{x} / \mathrm{OMS}-2$ and $\mathrm{CuO} / \mathrm{OMS}-2$ catalysts, respectively. Although they are similar at the beginning, the specific $\mathrm{CO}$ oxidation rate by $\mathrm{CuFeO}_{x} / \mathrm{OMS}-2$ was 2 times higher than that by $\mathrm{CuMnO}_{x} / \mathrm{OMS}-2$ and 5 times higher than that by $\mathrm{CuO} / \mathrm{OMS}-2$ after $48 \mathrm{~h}$ of reaction. The addition of $\mathrm{CuO}$ into the lattice of $\mathrm{Fe}_{x} \mathrm{O}_{y}$ reduces the temperature for complete $\mathrm{CO}$ oxidation [15]. Besides, $\mathrm{Fe}_{x} \mathrm{O}_{y}$ plays two roles of (i) catalyst under excess oxygen condition and (ii) oxidant (by lattice oxygen) under low oxygen condition [14]. The improvement in the stability of the $\mathrm{CuO}$ catalyst by adding $\mathrm{Fe}$ is consistent with those reported in the literature for mixed oxides of $\mathrm{Cu}$ and $\mathrm{Fe}$ [14-17]. Since iron is cheaper than the others, $\mathrm{CuFeO}_{x} / \mathrm{OMS}-2$ is more applicable as a commercial catalyst. It is also noticed that the stability of the catalysts is a very important factor affecting its ability in practical application.

\section{Conclusions}

The catalysts of $\mathrm{CuFeO}_{x}$ and $\mathrm{CuMnO}_{x}$ were impregnated on OMS-2 support and applied for the oxidation of CO at a low temperature of $\sim 35^{\circ} \mathrm{C}$. The addition of $\mathrm{Mn}$ and $\mathrm{Fe}$ into $\mathrm{CuO}$ was proven as an effective way to enhance the activity of $\mathrm{CuO} / \mathrm{OMS}-2$ catalyst for $\mathrm{CO}$ oxidation, where the specific reaction rate increases from 27.2 to $27.8-28.6 \mathrm{mmol}$ $\mathrm{CO} \cdot \mathrm{h}^{-1} \cdot \mathrm{g}_{\mathrm{Cu}}{ }^{-1}$. The stability of the material was improved by adding Mn and greatly enhanced by adding Fe. The catalytic activity decreased after $48 \mathrm{~h}$ of the reaction was recorded to be $82.4 \%$ and $55.4 \%$ for $\mathrm{CuO} / \mathrm{OMS}-2$ and $\mathrm{CuO} / \mathrm{OMS}-2$, respectively, but only $16.8 \%$ for $\mathrm{CuFeO}_{x} / \mathrm{OMS}-2$ catalyst in terms of specific rates. The high catalytic activity and stability of $\mathrm{CuFeO}_{x} / \mathrm{OMS}-2$ make it very promising as a stable and effective catalyst for $\mathrm{CO}$ oxidation at low temperature in practical applications.

\section{Data Availability}

The experimental data used to support the findings of this study are included in the manuscript. The other data are available from the corresponding author upon request.

\section{Conflicts of Interest}

The authors declare that there are no conflicts of interest regarding the publication of this paper.

\section{Acknowledgments}

The authors thank Ho Chi Minh City University of Technology (HCMUT) and An Giang University, VNU-HCM, for the time and providing facilities for this study.

\section{References}

[1] L. D. Prockop and R. I. Chichkova, "Carbon monoxide intoxication: an updated review," Journal of the Neurological Sciences, vol. 262, no. 1-2, pp. 122-130, 2007.

[2] S. Dey and G. C. Dhal, "Property and structure of various platinum catalysts for low-temperature carbon monoxide oxidations," Materials Today Chemistry, vol. 16, Article ID 100228, 2020.

[3] D. M. Patel, P. Kodgire, and A. H. Dwivedi, "Low temperature oxidation of carbon monoxide for heat recuperation: a green approach for energy production and a catalytic review," Journal of Cleaner Production, vol. 245, Article ID 118838, 2020.

[4] G. Xanthopoulou, V. A. Novikov, Y. A. Knysh, and A. Amosov, "Nanocatalysts for low-temperature oxidation of CO," Eurasian Chemico-Technological Journal, vol. 17, no. 1, pp. 17-32, 2014.

[5] J. Lin, X. Wang, and T. Zhang, "Recent progress in CO oxidation over Pt-group-metal catalysts at low temperatures," Chinese Journal of Catalysis, vol. 37, no. 11, pp. 1805-1813, 2016.

[6] H. Falsig, B. Hvolbæk, I. S. Kristensen et al., "Trends in the catalytic CO oxidation activity of nanoparticles," Angewandte Chemie, vol. 120, no. 26, pp. 4913-4917, 2008.

[7] M. Haruta, T. Kobayashi, H. Sano, and N. Yamada, "Novel gold catalysts for the oxidation of carbon monoxide at a temperature far below $0^{\circ} \mathrm{C}$," Chemistry Letters, vol. 16, no. 2, pp. 405-408, 1987.

[8] S. Dey and G. C. Dhal, "Deactivation and regeneration of hopcalite catalyst for carbon monoxide oxidation: a review," Materials Today Chemistry, vol. 14, Article ID 100180, 2019. 
[9] S. Singh and R. Prasad, "Physico-chemical analysis and study of different parameters of hopcalite catalyst for $\mathrm{CO}$ oxidation at ambient temperature," International Journal of Scientific and Engineering Research, vol. 7, no. 4, pp. 846-855, 2016.

[10] R. N. DeGuzman, Y.-F. Shen, E. J. Neth et al., "Synthesis and characterization of octahedral molecular sieves (OMS-2) having the hollandite structure," Chemistry of Materials, vol. 6, no. 6, pp. 815-821, 1994.

[11] X.-S. Liu, Z.-N. Jin, J.-Q. Lu, X.-X. Wang, and M.-F. Luo, "Highly active $\mathrm{CuO} / \mathrm{OMS}-2$ catalysts for low-temperature $\mathrm{CO}$ oxidation," Chemical Engineering Journal, vol. 162, no. 1, pp. 151-157, 2010.

[12] N. T. Q. Anh, "Binary copper and manganese oxide nanoparticle supported OMS-2 for enhancing activity and stability toward CO oxidation reaction at low temperature," Vietnam Journal of Science and Technology, vol. 56, no. 6, p. 741, 2018.

[13] C. U. Aniz and T. D. Radhakrishnan Nair, "A study on catalysis by ferrospinels for preventing atmospheric pollution from carbon monoxide," Open Journal of Physical Chemistry, vol. 1, no. 3, pp. 124-130, 2011.

[14] J.-L. Cao, Y. Wang, X.-L. Yu, S.-R. Wang, S.-H. Wu, and Z.-Y. Yuan, "Mesoporous $\mathrm{CuO}-\mathrm{Fe}_{2} \mathrm{O}_{3}$ composite catalysts for low-temperature carbon monoxide oxidation," Applied $\mathrm{Ca}$ talysis B: Environmental, vol. 79, no. 1, pp. 26-34, 2008.

[15] E. Amini, M. Rezaei, and M. Sadeghinia, "Low temperature $\mathrm{CO}$ oxidation over mesoporous $\mathrm{CuFe}_{2} \mathrm{O}_{4}$ nanopowders synthesized by a novel sol-gel method," Chinese Journal of Catalysis, vol. 34, no. 9, pp. 1762-1767, 2013.

[16] M. P. Yeste, H. Vidal, A. L. García-Cabeza et al., "Low temperature prepared copper-iron mixed oxides for the selective CO oxidation in the presence of hydrogen," Applied Catalysis A: General, vol. 552, pp. 58-69, 2018.

[17] P. Rezaei, M. Rezaei, and F. Meshkani, "Low temperature CO oxidation over mesoporous iron and copper mixed oxides nanopowders synthesized by a simple one-pot solid-state method," Process Safety and Environmental Protection, vol. 119, pp. 379-388, 2018.

[18] J. Zhang, X. Meng, C. Yu, G. Chen, and P. Zhao, "Heterogeneous $\mathrm{Cu} / \mathrm{OMS}-2$ as an efficient catalyst for the synthesis of tetrasubstituted 1, 4-enediones and 4H-pyrido [1, 2-a]-pyrimidin-4-ones," RSC Advances, vol. 5, no. 106, pp. 87221-87227, 2015.

[19] S. Sithambaram, E. K. Nyutu, and S. L. Suib, "OMS-2 catalyzed oxidation of tetralin: a comparative study of microwave and conventional heating under open vessel conditions," Applied Catalysis A: General, vol. 348, no. 2, pp. 214-220, 2008.

[20] K. J. Arun, A. K. Batra, A. Krishna, K. Bhat, M. D. Aggarwal, and P. J. Joseph Francis, "Surfactant free hydrothermal synthesis of copper oxide nanoparticles," American Journal of Materials Science, vol. 5, no. 3A, pp. 36-38, 2015.

[21] X. Lin, R. Li, Y. Zhang et al., "The role of surface copper species in $\mathrm{Cu}-\mathrm{Fe}$ composite oxide catalysts for the water gas shift reaction," International Journal of Hydrogen Energy, vol. 40, no. 4, pp. 1735-1741, 2015.

[22] T. Liu, Y. Yao, L. Wei et al., "Preparation and evaluation of copper-manganese oxide as a high-efficiency catalyst for $\mathrm{CO}$ oxidation and NO reduction by CO," The Journal of Physical Chemistry C, vol. 121, no. 23, pp. 12757-12770, 2017.

[23] J. Chen, J. Li, H. Li, X. Huang, and W. Shen, "Facile synthesis of Ag-OMS-2 nanorods and their catalytic applications in CO oxidation," Microporous and Mesoporous Materials, vol. 116, no. 1-3, pp. 586-592, 2008. 